Syntax Literate: Jurnal Ilmiah Indonesia p-ISSN: 2541-0849 e-ISSN: 2548-1398

Vol. 7, No. 1, Januari 2022

\title{
ILEGAL FISHING DI LAUT NATUNA UTARA: UPAYA PENANGANAN ILLEGAL FISHING SERTA PARA PELAKU SETELAH TERTANGKAP
}

\section{Arman Sobary Darmawijaya, Abdul Rivai Ras, Broto Wardoyo}

Fakultas Sekolah Kajian Stratejik dan Global jurusan Kajian Ketahanan Nasional

Universitas Indonesia, Salemba Jakarta, Indonesia

Email: armansobaryd19@gmail.com,rivai_ras@yahoo.com, broto09@ui.ac.id

\begin{abstract}
Abstrak
Illegal Fishing masih menjadi permasalahan klasik yang sedari dulu terus terjadi, meskipun hubungan bilateral sudah disepakati, perjanjian penjagaan maupun pengawasan bersama sudah ditandatangani. Namun, dalam implementasinya belum maksimal. Kurangnya armada kapal menjadi penyebab terbatasnya untuk melakukan pengawasan. Belum lagi regulasi hukum yang belum jelas terhadap para pelaku illegal fishing setelah mereka tertangkap. Oleh karena itu, pemerintah harus hadir dan mendukung penuh setiap pemenuhan kebutuhan armada kapal yang diperlukan, menegaskan kembali untuk bekerjasama bilateral dengan negara-negara lain agar menjaga kawasan perbatasan. Penelitian ini akan membahas mengenai penyebab terjadinya illegal fishing diperairan Natuna Utara serta bagaimana upaya penanganan para pelaku illegal fishing pasca tertangkap.
\end{abstract}

Kata Kunci: illegal fishing; perairan natuna utara; upaya penanganan pelaku illegal fishing pasca tertangkap

\section{Abstract}

Illegal fishing is still a classic problem that has always continued to occur, even though bilateral relations have been agreed, guarding and joint supervision agreements have been signed. However, in its implementation is not yet maximal. The lack of a fleet of ships is a limited cause for surveillance. Not to mention the unclear legal regulations against illegal fishing actors after they are caught. Therefore, the government must be present and fully support any fulfillment of the needs of the fleet of ships needed, reaffirming to cooperate bilaterally with other countries in order to safeguard the border area. This research will discuss the causes of illegal fishing in north Natuna water and how efforts to handle illegal fishing actors after being caught.

Keywords: illegal fishing; northern natuna waters; efforts to handle illegal fishing actors after being caught

Received: 2021-12-20; Accepted: 2022-01-05; Published: 2022-01-15

$\begin{array}{ll}\text { How to cite: } & \begin{array}{l}\text { Darmawijaya. A.S., Abdul Rivai Ras \& Broto Wardoyo (2022) Ilegal Fishing Di Laut Natuna Utara: Upaya } \\ \text { Penanganan Illegal Fishing Serta Para Pelaku Setelah Tertangkap. Syntax Literate: Jurnal Ilmiah Indonesia, } \\ \end{array} \\ & 7(1) . \\ \text { E-ISSN: } & \text { 2548-1398 } \\ \text { Published by: } & \text { Ridwan Institute }\end{array}$




\section{Pendahuluan}

Menjaga kedaulatan laut indonesia dari ilegal fishing merupakan sebuah upaya untuk mewujudkan pertumbuhan ekonomi nasional. Lebih dari itu, strategi serta implementasinya pun harus sungguh-sungguh dalam proses penanganannya. Indonesia sendiri memiliki wilayah perairan laut dengan luas sekitar 5,8 juta $\mathrm{km}^{2}$ (70 persen dari total wilayah indonesia) yang terdiri dari 2,8 juta $\mathrm{km}^{2}$ perairan laut nusantara; 0,3 Juta $\mathrm{km}^{2}$ perairan laut teritorial; dan 2,7 juta $\mathrm{km}^{2}$ laut Zona Ekonomi Eklusif Indonesia (ZEEI). Dengan luasnya perairan laut indonesia tersebut, tentunya memiliki sumber daya perikanan yang sangat besar (Kompas, 2020). Potensi perikanan yang melimpah itu secara langsung menarik perhatian pihak asing untuk ikut larut serta menikmati sumber daya ikan yang ada melalui kegiatan illegal fishing.

Kegiatan illegal fishing kerap terjadi di wilayah perairan Indonesia. Kapal-kapal asing yang berlalu-lalang untuk mencuri ikan di perairan tersebut merupakan negaranegara Asia yang memiliki batas garis laut yang berbatasan langsung dengan indonesia. Dengan adanya kejadian ini, tentu merugikan Indonesia (Kumparan, 2021). Modus yang dilakukan oleh para nelayan asing sangatlah beragam, mulai dengan menerapkan teknik flag of convinence atau modus dengan menggunakan suatu bendera negara pada kapal tanpa adanya memiliki hubungan asli antara pemilik kapal dan pengoperasiannya kepada negara tersebut. Kemudian alat illegal fishing selanjutnya adalah dengan mematikan alat pendeteksi posisi kapal seperti Automatic Identification System (AIS) dan Vessel Monitoring System (VMS) (Liputan.Com, 2020). Adapun Modus berikutnya dalam melakukan illegal fishing yaitu, para pelaku memalsukan dokumen dan identitas yang dipalsukan serta melibatkan jaringan pemilik kapal yang kompleks dan lintas negara sehingga pemilik kapal sebenarnya sulit dideteksi.

Salah satu wilayah yang menarik perhatian nelayan untuk melakukan illegal fishing adalah laut Natuna Utara. Laut dengan segala kekayaan yang terkandung didalamnya memiliki daya tarik yang luar biasa. Sumber daya ikan yang didapat dari hasil tangkapan itu terbagi kedalam dua kategori, yaitu ikan pelagis dan ikan demersal. Ikan pelagis merupakan ikan yang hidupnya selalu dipermukaan air antara 0-200 meter serta memiliki kebiasaan hidup berkelompok. Adapun ukuran ikan tersebut dibedakan menjadi pelagis besar dan kecil, seperti ikan tuna, ikan pedang, marlin cakalang, tenggiri, dan lainnya. Sedangkan untuk pelagis kecil seperti selir, teri, kembung, tongkol, dan lainnya. Selanjutnya ikan demersal dapat dijumpai di lingkungan pantai hingga laut dalam. Ikan demersal dibagi menjadi dua jenis, yaitu benthic dan bentapholagic. Beberapa jenis ikan di laut natuna yang potensial untuk dikembangan antara lain ikan jenis kerapu, tongkol krai, teri, tenggiri, ekor kuning, selar, kembung, kepiting, rajungan, udang windu, udang putih, cumi-cumi dan sotong.

Sumber daya perikanan yang menjadi primadona di laut natuna selalu menjadi daya tarik negara-negara tetangga seperti, Vietnam, Philipina, China, Thailand, dan Malaysia (Liputan6.com, 2015). Berkali-kali mereka melakukan pencurian ikan secara illegal dengan tidak memperdulikan aturan-aturan yang sudah jelas bahwa laut natuna sendiri merupakan kepulauan yang sah di miliki oleh Indonesia (Purwanto, 2014). Oleh 
karena itu, sinergitas Kkp, TNI, Bakamala, Polisi Perairan dan instansi lainnya yang terlibat memiliki peranan penting dalam menjaga perairan Indonesia dari para pelaku illegal fishing. Negara haruslah berani mengambil keputusan mengenai persoalan ini, memberikan sanksi yang keras bagi siapapun yang mencuri, serta melindungi kekayaan bahari sebagai industri perikanan yang menjadi penyangga ekonomi bangsa ini.

Strategi yang tepat harus diambil secara cepat dalam proses pencegahannya, teknologi canggih pun harus dihadirkan dalam setiap langkah guna meminimalisir kerugian yang akan terjadi. Operasi serta pelatihan yang terampil harus dimiliki oleh setiap orang yang akan menghadapi serta menyelsaikan pemsalahan yang ada di lapangan. Oleh karena itu negara, harus mendukung penuh terhadap para pahlawan yang terjun kelapangan, setiap alat yang dibutuhkan sebagai penunjang keberhasilan harus diberikan. Kemudian negara juga harus bernegosiasi dengan negara-negara di kawasan perbatasan terkait para pelaku illegal fishing yang tertangkap harus ada kejelasan, karena selain merugikan akan sumber daya perikanan, mereka juga akan menjadi beban negara jika tidak di pulangkan ke negaranya masing-masing. Hubungan bilateral serta diplomatik yang baik harus di hadirkan guna terjalinnya hubungan harmonis dengan negara-negara terkait yang telah dibina dengan baik sebelumnya. Adapun penelitian ini ingin mengungkapkan penyebab terjadinya illegal fishing yang sering terjadi dan berulang-ulang, serta upaya dan penanganan secara bilateral terkait para pencuri yang tertangkap oleh negara-negara yang terlibat.

Illegal fishing masih menjadi problematika serta kejahatan transnational yang sangat kompleks, pencurian di perairan Indonesia masih kerap terjadi (Jenifer L.Enck, 2003). Secara batas maupun hukum Internasional sudah jelas, namun tetap saja masih terjadi. Oleh karena itu, penanganan nya harus melibatkan seluruh lembaga terkait agar bisa bekerjasama serta solid dalam melakukan pencegahan dan penjagaan. lebih dari itu, diplomasi dengan negara terkait penting untuk dihadirkan, karena permaslahan ini timbul akibat negara yang bersangkutan lengah dalam penjagaan terhadap para pelaku illegal fishing. Sehingga permasalahan ini menarik untuk dikaji mengenai penyebab terjadinya illegal fishing di perairan natuna utara? Bagaimana upaya pemerintah dalam proses penanganannya? serta langkah apa yang di ambil oleh pemerintah pasca penangkapan para pelaku illegal fishing terutama dari negara asing?

\section{Metode Penelitian}

Adapun penelitian ini adalah penelitian deskriptif dengan menggunakan metode kualitatif (Cresswell, 2017), data serta informasi yang didapt melalui studi kepustakaan dan wawancara langsung dengan pihak yang kompeten dan memiliki informasi. Data yang diperoleh secara langsung dilapangan kemudian di analisis untuk diinterpretasikan agar sesuai dengan makna yang terkandung dalam data dan informasi tersebut. Adapun pihak yang memberikan informasi terkait kepentingan penelitian ini adalah TNI AL dan Peneliti dari LIPI yang sudah melakukan penelitian di wilayah perairan Laut Natuna Utara pada bulan Mei 2021 lalu. 


\section{Hasil dan Pembahasan}

\section{A. Potensi Kelautan Natuna}

Potensi sumber daya kelautan Natuna sangatlah besar. Memiliki luas wilayah laut 262.197,07 km², menjadikan laut ini sebagai surganya dunia perikanan, dengan potensi sumber daya alam dan lautnya yang melimpah (Mahabror \& Hidayat, 2018). Potensi yang besar itu belum di manfaatkan secara optimal, baik ekplorasi maupun ekploitasinya. Oleh karena itu, pemenuhan kebutuhan kapal-kapal serta alat canggih harus di upayakan guna terwujudnya negara dengan penghasil kualitas ikan terbaik di dunia (Prof Rokhmin, 2017). Pemerintah sendiri mulai saat ini haruslah fokus terhadap sumber daya laut. Dengan memanfaatkan laut natuna secara maksimal, tentu akan menambah serta membangkitan industri perikanan Indonesia yang sampai saat ini masih belum bisa di manfaatkan potensi lautnya dengan baik dan maksimal. Selain itu, pentingnya edukasi kepada masyarakat untuk tidak membuang sampah sembarangan ke laut karena itu akan berdampak buruk terhadap perikanan yang ada didalamnya. Ketika kepedulian itu terealisasikan maka secara tidak langsung akan memberikan nilai positif untuk masa kini dan mendatang, dengan melimpah ruahnya sumber daya perikanan yang telah kita jaga lautnya dari sampah. Sehingga Indonesia sendiri akan menjadi pemasok ikan terbesar dunia jika optimalisasinya dijalankan dengan baik (Muhamad, 2016).

Pemerintah harus terus meningkatkan upaya-upaya maupun terobosan baru secara maksimal, tidak hanya dari segi pengawasan saja, melainkan sisi lain seperti peningkatan alat-alat yang canggih, kapal-kapal yang bisa bersaing dengan para pelaku illegal fishing, serta pendetiksi yang mampu memonitoring pada saat kapalkapal akan masuk ke wilayah perairan indonesia. Sebelumnya pemerintah hanya fokus terhadap sumber daya darat saja, sedangkan sumber daya kelautan serta potensinya kurang dimaksimalkan. Potensi yang ada di laut natuna sendiri ada sekitar 23.400 ton potensi cumi-cumi pertahun, 1.400 ton lobster per tahun, ada pula 2.300 ton lebih kepiting per tahun, dan ada 9.700 ton lebih rajungan pertahun. Ketika potesnsi-potensi tersebut di kelola dengan baik dan maksimal akan menjadi sebuah nilai berharga untuk menunjang lajur pertumbuhan ekonomi negara.

\section{B. Illegal Fishing di Perairan Natuna Utara}

Para pelaku illegal fishing menangkap ikan di perairan Natuna Utara dengan menggunakan kapal-kapal besar. Sehingga pengawasan yang di lakukan sangatlah sulit dikarenakan armada yang terbatas serta luasnya laut Natuna Utara. Sampai saat ini jumlah armada yang tersedia berjumlah $30 \mathrm{kapal}$, sedangkan idealnya untuk melakukan pengawasan agar maksimal yaitu sebanyak 78 kapal. Oleh karena itu mulai saat ini khususnya Kementrian Kelautan dan Perikanan haruslah mulai berbenah diri di setiap lini, terutama perlunya untuk menambah jumlah kapal. Sinergitas semua lembaga perlu di hadirkan agar pencurian di perairan Indonesia menurun. Dari data PSDK Kementrian Kelautan dan Perikanan kapal-kapal pelaku IUU fishing, baik kapal ikan Indonesia (KII) maupun (KIA) dapat dilihat pada tabel di bawah ini. 
Tabel 1

Data Kapal Pelaku Iuuf Yang Di Tangkap Di Perairan Laut Natuna Utara

Tahun 2016-2021 Update 30 April 2021

Tahun Jumlah Kapal Tertangkap

\begin{tabular}{cc}
\hline 2016 & 83 \\
\hline 2017 & 75 \\
\hline 2018 & 50 \\
\hline 2019 & 27 \\
\hline 2020 & 24 \\
\hline 2021 & 8 \\
\hline
\end{tabular}

*sumber Ditjen PSDKP Kementrian Kelautan dan Perikanan, 2021

Berdasarkan data enam tahun terakhir di atas pencurian ikan di perairan Natuna Utara mulai menurun dan ini menandakan bahwa pengawasan serta penjagaan benar-benar ditingkatkan.

\section{Penyebab Terjadinya Illegal Fishing}

Adapun penyebab terjadinya illegal fishing di perairan laut Natuna Utara antara lain, adalah:

1. Sumber daya ikan di perairan Natuna Utara sendiri sangat melimpah, hal ini menyebabkan laut Natuna Utara sendiri menjadi primadona nelayan asing. Selain sumberdaya nya melimpah, laut Natuna merupakan Zona Ekonomi Ekslusif Indonesia (ZEEI), artinya laut tersebut berbatasan dengan laut asing salah satunya dengan Vietnam. Ketika mereka melakukan penangkapan ikan di Laut vietnam dengan alat tangkap berbahya serta merusak habitat tempat ikanikan untuk melakukan berkembang biak, maka rumah ikan akan hilang, sehingga ikan-ikan lari dan berpindah ke perairan natuna. Di Indonesia sendiri Kementerian Kelautan dan Perikanan mengatur tentang alat-alat yang boleh dan tidak ketika melakukan penangkapan ikan di perairan laut Indonesia (Kompas, 2021). Adapun alat yang diperbolehkan seperti kelompok jaring lingkar, jaring tarik, kelompok jaring hela, jaring angkat, jaring insang, alat tangkap yang dijatuhkan atau ditebar, kelompok alat pancing, dan alat tangkap lainnya. Kelompok alat penangkap ikan (API) jaring lingkar terdiri atas, pukat cincin, pukat pelagis besar dengan satu kapal, pukat cincin teri dengan satu kapal, dan jaring lingkar tanpa tali kerut. Kemudian kelompok alat penangkap ikan jaring tarik, yaitu jaring tarik pantai, payang, jaring tarik sempadan, dan jaring tarik berkantong. Sedangkan jaring hela yaitu jaring hela udang berkantong, jaring hela ikan berkantong. Alat pancing yang dilarang yaitu kelompok API jaring hela seperti pukat hela dasar berpalang, puka hela dasar udang, pukat hela kembar berpapan, pukat hela dasar dua kapal, pukat hela pertengahan dua kapal, dan pukat ikan. Kelompok API jaring tarik, terdiri dari dogol, pair seine, cantrang dan lampara dasar, sementara kelompok API perangkap terdiri atas perangkat ikan peloncat dan kelompok ikan lainnya terdiri atas muro ami. 
2. Masih terbatasnya kemampuan para nelayan Indonesia untuk memanfaatkan potensi sumber daya yang ada di laut Natuna. Kapal-kapal kecil yang digunakan oleh nelayan Indonesia menyebabkan mereka kesulitan untuk sampai ke Zona Ekonomi Eklusif Indonesia (ZEEI).

3. Terbatasnya pengawasan disebabkan oleh kurangnya armada kapal. Padahal sinergitas dari berbagai intansi sudah kompak mulai dari Kementrian Kelautan dan Perikanan, TNI AL, Bakamala dan Polisi Air. Akan tetapi, kurangnya kapal untuk melakukan pengawasan menjadi hambatan. Saat ini yang tersedia sebanyak 30 kapal untuk melakukan pengawasan. Padahal idealnya membutuhkan lebih dari 70 kapal pengawasan.

4. Fokus pemerintah dalam upaya penyelamatan sumber daya kelautan baru beberapa tahun ke belakang sebelumnya hanya fokus terhadap sumber daya yang ada di darat saja. Padahal jika di manfaatkan secara optimal akan memberikan dampak yang sangat luar biasa terhadap lajur pertumbuhan ekonomi negara.

5. Terjadinya illegal fishing di picu oleh permintaan serta kebutuhan ikan tertentu yang memiliki nilai jual ekonomi dengan harga tinggi, ikan-ikan pilihan tersebut akan di jual di restoran-restoran mewah di luar negeri, selain mahal ikan-ikan yang berada di laut Natuna Utara memiliki kualitas tinggi untuk dijual dipasaran Internasional. Mereka menggunakan kapal-kapal besar dalam melakukan proses penangkapannya. Kemudian kapal tersebut dilengkapi dengan teknologi canggih serta didalamnya sudah dilengkapi tempat penyimpanan ikan, dengan adanya tempat tersebut kualitas ikan yang ditangkap akan tetap segar meskipun sudah lewat beberapa hari.

\section{Penanganan Illegal Fishing Serta Tindakan Bagi Para Pelaku Pasca Tertangkap}

Keterlibatan negara bersangkutan perlu dihadirkan dalam upaya penanganan illegal fishing, mengingat pencurian yang dilakukan bukan hanya sekali saja melainkan berkali-kali. Ini menandakan adanya kelonggaran penjagaan dan pengawasan dari dua negara. Sehingga mereka dengan mudah keluar masuk laut Indonesia. Setidaknya ada beberapa negara yang berbatasan langsung dengan laut Natuna Utara. Oleh karena itu, perlu adanya perhatian khusus terhadap negaranegara tersebut baik dari segi pencurian maupun penanganannya agar tidak menimbulkan polemik terhadap hubungan bilateral yang telah dibina dengan baik. Adapun negara-negara yang berbatasan langsung dengan perairan Natuna Utara ialah, pada bagian utara Natuna berbatasan langsung dengan Vietnam dan kamboja dan di bagian timur berbatasan langsung dengan Malaysia Timur.

1. Vietnam

Nelayan yang kerap melakukan pencurian ikan berasal dari negara Vietnam. Padahal di tahun 2010 Indonesia telah memberikan negosiasi dengan negara Vietnam yang disampaikan langsung oleh Menteri Kelautan dan Perikanan (MKP) Fadel Muhammad yang meminta komitmen Vietnam untuk 
mengehentikan masuknya kapal ilegal ke Indonesia. Komitmen tersebut disampaikannya ketika melakukan pertemuan resmi dengan Duta Besar Luar Biasa dan Berkuasa Penuh Republik Sosialis Vietnam, H.E Nguyen Huu Dzung. Dalam pertemuan tersebut juga dibahas mengenai rancangan kesepakatan bersama kedua negara dalam lingkungan kerjasama sektor perikanan. Kementerian Kelautan dan Perikanan berkeinginan untuk membangun kerjasama lebih lanjut dengan Vietnam di bidang budidaya perikanan, pengelolaan pasca-panen, dan keamanan pangan.

Kerjasama perikanan dan kelautan telah mengagendakan kedatangan Presiden RI ke Vietnam untuk ikut menandatangani MoU bidang kelautan dan perikanan. Selain itu, dibicarakan rencana kerjasama dengan Vietnam di bidang produksi dan pemasaran hasil perikanan khususnya untuk jenis catfish. Sebelumnya kerjasama antara Indonesia-Vietnam telah ditandatangani pada tahun 2003 (Hibatullah, 2017). Pertemuan demi pertemuan telah dilakukan beberapa kali oleh kedua negara tersebut. Akan tetapi, negosiasi yang sedari dulu berjalan belum menemukan titik terang. Pertemuan terakhir tahun 2018 Presiden Joko Widodo mendorong agar Vietnam dengan cepat menyelesaikan sengketa perbatasannya dengan Indonesia saat bertemu dengan Presiden Tran Dai Quang di Hanoi pada tanggal 11-12 September.

Klaim historis masih menjadikan dalih para nelayan Vietnam melakukan pencurian ikan di wilayah perairan Natuna Utara (Riska, 2017). Hingga saat ini masih banyak nelayan dari Vietnam yang melakukan pencurian ikan di laut Natuna Utara. Pada tanggal 27 mei terjadi aksi kejar-kejaran antara kapal Indonesia dengan kapal ikan asing berbendera Vietnam di Laut Natuna Utara. Namun, aksi pencurian tersebut berhasil digagalkan oleh kapal pengawas Indonesia.

Kemudian di susul kembali dengan aksi pencurian oleh pelaku dari negara yang sama pada tanggal 27 Agustus 2021 dan berhasil menangkap 4 kapal asing. Arief Sulistyanto mengatakan modus dari operandi dari empat kapal asing ini adalah masuk ke wilayah perairan Indonesia pada malam hari dan keluar menjelang matahari terbit. Dengan demikian, mereka dapat menghindari operasi dari petugas. Kepolisian mencatat kapal KG 1448 TS dan KG 90721 TS sudah beroperasi selama 12 tahun sampai dengan saat ini. Dua kapal ini kerkapasitas muatan total 85 ton. Kapal KG 1448 TS memiliki delapan palka atau total keduanya 17 palka kapasitasnya 5 ton.

Dengan asumsi kapal tersebut membawa hasil muatannya sebulan sekali dan harga ikan 50 ribu per kilogram. Maka, selama 12 tahun ini total kerugian negara bisa mencapai Rp 612 miliar atau kerugian per tahun Rp 66 miliar. Dengan jumlah kerugian yang besar tersebut harusnya Indonesia sendiri bertindak tegas terhadap negara yang bersangkutan. Penangkapan ikan yang berulang-ulang seolah-olah tidak mengahargai hubungan bilateral yang sudah dijalin dengan baik. 
Selanjutnya bagaimana upaya penanganan terhadap para pelaku illegal fishing Non Yuridiksi. Ini menjadi sebuah catatan penting yang terjadi dilapangan dan kurangnya perhatian pasca operasi penangkapan. Dimana hukum maupun penyidiknya harus jelas agar tidak tumpang tindih dan saling melempar ketika di lapangan. Menurut UU No 31 tahun 2004 tentang perikanan bahwa yang berhak melakukan penyidikan saat terjadi penangkapan ialah Psdkp dan TNI AL. Para pelaku illegal fishing biasanya ketika tertangkap oleh pengawas akan diserahkan kepada TNI AL dan Psdkp. Adapun para nelayan asing yang tidak mendapatkan hukuman melainkan tahanan non yuridiksi di bawa ke Ranai, lanal atau Detensi untuk di tampung sampai mereka di pulangkan ke negara masing-masing. Pada saat proses penangkapan, yang ditangkap hanya Kapten dan Teknisi saja sedangkan yang lainnya sebagai tahanan non yuridiksi. Selain merugikan negara para pelaku ini menjadi beban negara apabila tidak secepatnya di pulangkan. Pemulangannya sendiri bisa dilakukan secara Ship to Ship yaitu sudah melakukan perjanjian dengan negara yang bersangkutan untuk bertemu di Zona Ekonomi Eklusif, sehingga para pelaku bisa di pindahkan ke kapal negaranya. Kemudian solusi selanjutnya dengan menggunakan jalur udara, diplomasi melalui Kementrian Luar Negeri serta di bantu oleh pihak Imigrasi dalam proses pemulangannya.

2. Malaysia

Pencurian Ikan masih sering dilakukan nelayan asing dari Malaysia di Laut Natuna Utara. Padahal sebelumnya Indonesia-Malaysia telah menjalin kerjasama di bidang perikanan. Meliputi penanganan serta pengawasan mengenai permasalahan nelayan yang mecuri ikan di kawasan perairan perbatasan. Menteri Susi mengungkapkan sejumlah kerjasama yang rencananya bakal ditingkatkan melalui penandatanganan nota kesepahaman (MoU), antara lain pertukaran data satelit di tahun 2016. Kemudian pertemuan kembali terjadi di tahun 2019 untuk menindaklanjuti perjanjian-perjanjian sebelumnya, beberapa poin yang di bahas dalam kunjungan tersebut terkait kelautan dan perikanan dibahas dalam kunjungan tersebut diantaranya kerjasama antara Aparat Penguatkuasaan Maritim Malaysia (APPM), yang merupakan kesatuan penjaga pantai Malaysia, dengan Satuan Tugas Pemberantasan Penangkapan Ikan Secara Ileggal. Selain itu, kerjasama lainnya adalah diskusi isu kapal Malaysia yang ditangkap di perairan Indonesia, rencana penandatanganan Joint Comunique, MoU tentang kerjasama di bidang kelautan dan perikanan, dan Peninjauan kembali MoU tentang pedoman Umum tentang Penanganan terhadap Nelayan oleh Lembaga Penegak Hukum di Laut Republik Indonesia dan Malaysia. Meskipun perjanjian mengenai pengawasan di laut perbatasan telah disepakati. Akan tetapi, tetap saja para pencuri ikan masih terus terjadi hingga saat ini. Terbukti pada tanggal 2 Juni 2021 telah terjadi pencurian ikan kembali yang dilakukan oleh nelayan asal Malaysia, sebanyak 3 kapal melakukan pencurian dengan menggunakan alat tangkap pukat trawl di Zona Ekonomi 
Eklusif Indonesia. Disusul minggu selanjutanya terjadi penangkapan lagi oleh Kapal Patroli Hiu 01 kementrian Kelautan dan Perikanan yang menangkap KM PKB 1472, Kapal pencuri ikan berbendera Malaysia. Kepala Dinas Kelautan dan Perikanan Provinsi Riau Herman mengatakan Kapal KM PKFB 1472 ini di nahkodai oleh warga Myanmar bernama Myo Jeng Soon Htun dengan anak buah kapal sebanyak14 orang dan semua berkebangsaan Myanmar. Kapal ini telah melanggar pasal 92 jo pasal 26 ayat (1) pasal 93 ayat (2) pasal 27 dan UU Nomer 45/2009 tentang perubahan atas UU Nomer 31/2004 tentang perikanan. Oleh karena itu pemerintah harus benar-benar fokus, serta ketat melakukan pengawasan di perairan tersebut.

Pemerintah pusat sendiri berencana untuk membangun bandara di wilayah natuna untuk keperluan sipil dan militer (Natuna, 2020). Tujuan nya agar memudahkan serta pengawasan menjadi lebih efektif. Selain itu, keberadaan bandara di Pulau Laut tersebut juga bisa memperkuat NKRI. Dengan adanya rencana itu pemerintah daerah serta pusat harus bersinergi dalam menyiapkan dan mengkaji wilayah yang strategis untuk dijadikan bandara tersebut. Wakil Bupati Natuna Rodial Huda berharap selain pembangunan bandara, dibangun pula kawasan terpadu untuk bidang politik, ekonomi, sosial, budaya, dan pertahanan keamanan. Dengan begitu, Indonesia seperti memiliki kapal induk yang tidak bisa ditenggelamkan. Kemudian kedepannya bandara di pulau Laut Natuna, dibangun pula pangkalan militer yang tangguh dan kuat seperti pangkalamn militer di Hawaii dan Okinawa.

3. Kamboja

Selain negara Vietnam dan Malaysia ada negara lain yang dekat dan berbatasan dengan laut Natuna Utara yaitu Kamboja (Deni \& Sahri, 2017). Dengan sumber ikan yang melimpah menjadikan nelayan dari negara itu tertarik untuk melakukan illegal fishing. Terbukti pada tahun 2004 dua kapal nelayan asing beserta 36 anak buah ditangkap oleh tim Patroli Gabungan Tentara Nasional Indonesia Angkatan laut dan petugas keamanan seumber daya kelautan-perikanan di perairan Laut Natuna. Para pencuri ikan tersebut berasal dari Kamboja dan Vietnam. Mereka mengelabui petugas agar tidak tertangkap dengan menggunakan bendera dan nama kapal berbahasa Indonesia.

Kapal-kapal tersebut tentu dilengkapi dengan teknonologi tinggi seperti jaring jenis trawl atau alat tangkap modern berupa jaring yng terdiri dari kantong berbentuk empat persegi atau kerucut. Sehingga jaring ini memudahkan nelayan untuk menangkap ikan dalam jumlah besar. Sedangkan kelebihan lainnya dilengkapi pula dengan radar. Ketika tertangkap oleh tim gabungan, masingmasing mereka membawa sekitar lima ton ikan. Kemudian mereka ditahan dan dibawa ke dermaga pelelangan ikan dikawasan Sungai rengas, yang selanjutnya mereka di deportasi ke negara asalnya kecuali nahkoda dan kepala kamar mesin tentu harus menjalani proses hukum. 
Kasus serupa pencurian ikan kembali dilakukan oleh nelayan dari kamboja. Kapal Pengawas KKP yaitu Orca 3 dan KP Hiu 11 berhasil menangkap dua KIA ilegal berbendera Vietnam beserta 18 nelayan Vietnam dan empat nelyan kamboja di Laut Natuna Utara. Oleh karena itu, kamboja seharusnya mengawasi dan menjaga para nelayan nya untuk tidak keluar batas wilayah perairannya dan mencuri ikan di perairan negara lain. Mengingat Indonesia sendiri secara histori memiliki peranan penting dalam proses perdamaian untuk kamboja ditengah konflik yang terjadi. Indonesia sebagai negara yang menganut perdamaian tentu menyelsaikan kebuntuan dengan turut campur dalam mengtasi konflik yang terjadi disana. Berlatar belakang kedekatan negara menjadikan Indonesia sebagai kunci keberhasilan misi UNTAC yang diturunkan oleh PBB untuk menyelsaikan konflik panjang yang dialami oleh Kamboja. Sudah sepantasnya negara Kamboja membalas budi, salah satunya dengan memperketat penjagaan dan pengawasan di perairan yang mendekati Zona Ekonmi Eklusif indonesia ZEEI. Sehingga dengan saling menghormati dan menghargai bisa meneruskan hubungan bilateral yang baik.

\section{Kesimpulan}

Berdasarkan permasalahan, upaya, serta potensi yang ada maka pemerintah harus mengerahkan segenap kemampuan yang ada untuk melindungi perairan Laut natuna Utara dengan melengkapi sarana-prasarana, mulai dari membangun bandara agar akses mobilitas sipil maupun militer mudah, kemudian dibangun pula kawasan terpadu untuk bidang politik, ekonomi, sosial, budaya, dan pertahanan keamanan, serta perlu adanya penambahan armada kapal agar maksimal dalam melakukan patroli penjagaan maupun pengawasan.

Sinergitas setiap instansi harus dihadirkan dalam upaya penangan terhadap para pelaku ilegal fishing, langkah yang diambil harus cepat oleh negara dengan melibatkan Kementrian Luar Negeri dalam proses pemulangannya. Sehingga para pelaku asing yang masuk ke wilayah ZEEI dan melakukan pencurian ikan di laut Indonesia segera dipulangkan agar tidak menjadi beban negara. Oleh karena itu, kerjasama bilateral harus ditingkatkan lagi terutama dalam penjagaan dan pengawasaan di area laut perbatasan agar hubungan yang telah dibina dengan baik, menjadi lebih baik tanpa adanya konflik. 
Ilegal Fishing Di Laut Natuna Utara: Upaya Penanganan Illegal Fishing Serta Para Pelaku Setelah Tertangkap

\section{BIBLIOGRAFI}

Cresswell, J. W. (2017). Research Design: Pendekatan Kualitatif, Kuantitatif, dan Mixed (Edisi Ketiga). Yogyakarta: Pustaka Belajar. Google Scholar

Deni, Fitra, \& Sahri, Lukman. (2017). Upaya Diplomasi Indonesia Terhadap Klaim China Atas Zona Ekonomi Eksklusif Indonesia Di Laut Natuna. International \& Diplomacy. Google Scholar

Hibatullah, Fariz. (2017). Implementasi Unilateralisme ZEE Indonesia Terkait Kasus IUU Fishing Studi Kasus: IUU Fishing Indonesia-Vietnam 2014-2015. Universitas Airlangga. Google Scholar

Jenifer L.Enck. (2003). "The United Nations Convetion Againts Transnational Organized Crime:Is it All that is Cracked up tu be". Syracus Journal of International Law, 30, 374-375. Google Scholar

Kompas. (2020). Potensi lestari sumber daya ikan laut indonesia diperkirakan sebesar 12,54 juta ton pertahun yang tersebar di perairan wilayah indonesia dan perairan ZEE.

Kompas. (2021). Kementrian Kelautan dan Perikanan (KKP) menyusun daftar alat penangkap ikan (API) yang diperbolehkan dalam aturan baru”. Kompas.Com.

Kumparan. (2021). Sekjen Kementrian dan Kelautan dan Perikanan (KKP), Antam Novambar, mengungkapkan sejak 2020 hingga 2021 kerugian negara mencapai 30 TRILIUN. Kumparan.Com.

Liputan.Com. (2020). Kepala Badan Riset dan Sumber Daya Manusia Kelautan dan Perikanan (BRSDM) KKP Sjarief Widjaja, Terdapat kewajiban bagi kapal berukuran 300 Gros Ton (GT) untuk mengaktifkan AIS. Namun yang seringkali terjadi an VMS tersebut agar keberadaan kegiatannya tida.

Liputan6.com. (2015). Dari data Direktorat Jendral PSDKP, sebanyak 107 kapal tersebut rinciannya, dari Malaysia $6 \mathrm{kapal,}$ China $1 \mathrm{kapal}$, Thailand $21 \mathrm{kapal,}$ Filipina 34 kapal,Vietnam 39 kapal, Papua 2 kapal, dan Indonesia 4 kapal. Sedangkan 10 kapal yang ditenggelamkan hari ini.

Mahabror, Dendy, \& Hidayat, Jenjen Jenhar. (2018). Analisis Kerugian Ekonomi Akibat Illegal Fishing di Zona Ekonomi Eksklusif Perairan Natuna. Prosiding Seminar Nasional Kelautan Dan Perikanan IV, 263-270. Google Scholar

Muhamad, Simela Victor. (2016). Illegal fishing di perairan indonesia: permasalahan dan upaya penanganannya secara bilateral di Kawasan. Jurnal Politica Dinamika Masalah Politik Dalam Negeri Dan Hubungan Internasional, 3(1). Google Scholar

Natuna, Dinas Kominfo Kabupaten. (2020). Tim Redaksi. Google Scholar 
Arman Sobary Darmawijaya, Abdul Rivai Ras, Broto Wardoyo

Prof Rokhmin. (2017). Rendahnya pemanfaatan potensi ikan tersebut dikarenakan sedikitnya kapal modern dengan kapasitas 20-30 GT. Republika.co.id.

Purwanto, Harry. (2014). Rute Penerbangan Di Atas Alur Laut Kepulauan; Perspektif Indonesia. Perspektif Hukum, 14(1), 1-17. Google Scholar

Riska, Ela. (2017). Diplomasi Maritim Indonesia Terhadap Aktivitas Penangkapan Ikan Ilegal (Illegal Fishing) oleh Nelayan China di ZEE Perairan Kepulauan Natuna. Jurnal Diplomasi Pertahanan, 3(2). Google Scholar

\section{Copyright holder:}

Arman Sobary Darmawijaya, Abdul Rivai Ras, Broto Wardoyo (2022)

First publication right:

Syntax Literate: Jurnal Ilmiah Indonesia

This article is licensed under:

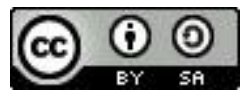

